\title{
Crescimento e produtividade do tomateiro em cultivo hidropônico NFT em função da concentração iônica da solução nutritiva
}

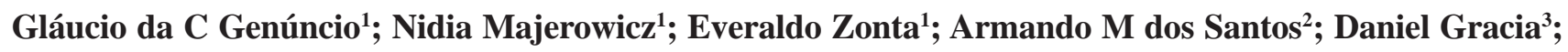 \\ Clarissa Regina M Ahmed ${ }^{3}$; Marcelle G da Silva ${ }^{4}$ \\ ${ }^{1}$ UFRRJ, BR 465, Km 7, 23851-970 Seropédica-RJ; E-mail: glauciogenuncio@ hotmail.com; ${ }^{2}$ UFRGS-DPFA; ${ }^{3}$ Estudante Eng. \\ Agronômica; ${ }^{4}$ FAPERJ/UFRRJ Bolsista-Programa jovens talentos para a ciência
}

\begin{abstract}
RESUMO
O cultivo hidropônico do tomateiro é uma técnica com a qual pode-se obter maior produtividade e melhoria no controle de diversos fatores durante o ciclo produtivo. Entretanto, essa técnica ainda requer aprimoramento em vários aspectos, dentre eles, as doses de nutrientes na solução nutritiva. Neste sentido, um experimento foi conduzido em casa de vegetação equipada com sistema hidropônico tipo fluxo contínuo de nutrientes (nutrient film technique; NFT). Foram utilizadas as cultivares de tomate UC-82, Saladinha e T-93 supridas com solução nutritiva de Hoagland nas concentrações iônicas 50\%; 75\% e 100\%. Na última coleta de frutos, aos 138 dias após a transferência para o sistema NFT, colheram-se as plantas e avaliaram-se o acúmulo de massa na parte aérea, massa fresca de fruto, número de frutos por planta, massa fresca total de frutos por planta, teor de sólidos solúveis totais $\left({ }^{\circ} \mathrm{Brix}\right)$ e produtividade. As características genotípicas das cultivares influenciaram fortemente a produtividade. De modo geral, as diferentes concentrações iônicas das soluções nutritivas, nas condições em que foi desenvolvido o trabalho, não influenciaram a produtividade e o acúmulo de massa dos tomateiros. Portanto é recomendável o uso de soluções de menor concentração iônica para o cultivo de tomateiros UC-82, Saladinha e T-93 em sistema hidropônico NFT, nas condições climáticas de Seropédica, Rio de Janeiro.
\end{abstract}

Palavras-chave: Lycopersicon esculentum Mill., condutividade elétrica, cultivares de tomateiro, hidroponia.

\begin{abstract}
Growing and yield of tomato in hydroponic cultivation as a result of the ionic concentration of the nutritive solution

The tomato hydroponics cultivation is a technique that provides high productivity and a better control of several factors during the production cycle. However, this technique needs improvements such as adequate dosage of nutrients in the nutritive solution. An experiment was carried out in a greenhouse equipped with a nutrient film technique system (NFT). Three commercial cvs. of tomato, UC82, Saladinha, and T-93, were grown with three Hoagland's solution concentrations, 50\%; 75\%; and 100\%. In the last fruit harvest, 138 days after transference to the NFT system, the accumulation of shoot dry mass, the fruit fresh mass, the number of fruits per plant, the total fresh biomass per plant, the total content of soluble solids ( ${ }^{\circ}$ Brix) and the productivity, were evaluated. The genotypic characteristics of the cvs. affected strongly the productivity. Generally the ionic concentrations of the nutrition solution did not influence the productivity and the tomato plants mass accumulation. Thus, the usage of solutions with lowest ionic concentration is recommended for the cultivation of the UC-82, Saladinha and T-93 tomatoes, in NFT hydroponics system, in the climatic conditions of Seropédica, Rio de Janeiro State.
\end{abstract}

Keywords: Lycopersicon esculentum Mill., electrical conductivity, tomato cultivars, hydroponics.

(Recebido para publicação em 5 de maio de 2005; aceito em 29 de abril de 2006)

$\mathrm{O}$ cultivos hidropônicos possibilitam a obtenção de produtos de boa qualidade quando comparados aos sistemas convencionais, devido a maior uniformidade na colheita e eficiência no uso da água para fins de irrigação (Faquin $e t$ al., 1996). Teixeira (1996) destaca que em quase todos os estados brasileiros, cultivam-se hortaliças em hidroponia, tendo como culturas principais alface, rúcula, pimentão, morango e tomate. Outras hortaliças estão restritas a pequenas áreas experimentais, ainda sem representatividade no mercado, como é o caso do agrião, salsinha e melão (Costa et al., 2000). De modo geral, os cultivos hidropônicos requerem acompanhamento permanente do funcionamento do sistema, principalmente quanto ao forne- cimento de energia elétrica e ao controle das características químicas e físicas da solução nutritiva (Faquin et al., 1996).

No cultivo do tomate em hidroponia, o sistema mais utilizado é o fluxo laminar de nutrientes (NFT). No entanto, este sistema ainda carece de informações quanto aos aspectos de montagem e manutenção, exigindo a intensificação de pesquisas visando, principalmente, as condições locais (Moraes, 1997). Dentre os fatores de produção, a nutrição mineral é essencial para elevar a produtividade e melhorar a qualidade do produto (Furlani et al., 1999). Todos os nutrientes essenciais devem ser fornecidos em níveis compatíveis às exigências de cada espécie e de acordo com a fase de desenvolvimento (Haag et al.,
1993). Martinez (2002) afirma que para a minimização de erros experimentais na análise de sintomas induzidos pelo excesso ou deficiência de um nutriente em solução nutritiva é recomendável a utilização de concentrações mínimas. A definição das concentrações mínimas deve ser objeto de estudo, tendo em vista as diferenças genotípicas, ambientais e as demandas associadas às diferentes fases do desenvolvimento. Em geral, há tendência de redução da concentração iônica da solução nutritiva nos cultivos hidropônicos comerciais, especialmente em ambientes cujas temperaturas, luminosidade e umidade relativa são altas e nas estações mais quentes do ano (Furlani et al., 1999; Cometti, 2003). Cabe ressaltar que o uso racional de adubos, além de reduzir custos e garantir qua- 


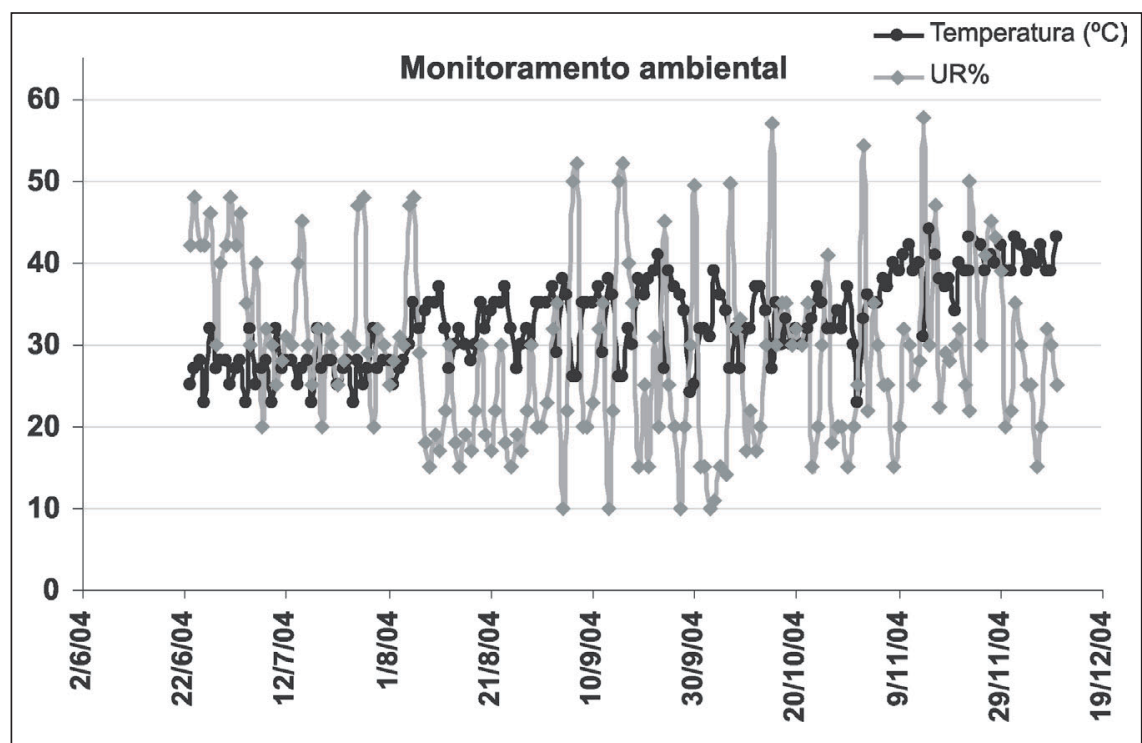

Figura 1. Temperatura máxima $\left({ }^{\circ} \mathrm{C}\right)$ e umidade relativa (UR\%) em ambiente protegido durante os meses de junho a dezembro de 2004, no município de Seropédica, Rio de Janeiro. Seropédica, UFRRJ, 2004.

lidade da produção, minimiza a contaminação do ambiente e suas conseqüências, como a eutrofização de águas superficiais e subterrâneas e o acúmulo de elevados teores de nitrato nos lençóis freáticos e nas plantas (Goto \& Tivelli, 1998).

No manejo da solução nutritiva, fatores como temperatura (níveis ótimos em torno de $24 \pm 3^{\circ} \mathrm{C}$ ), $\mathrm{pH}$ (valores adequados entre 5,5 a 6,5) e condutividade elétrica da solução nutritiva (faixa ótima entre 1,5 a 4,0 $\mathrm{dS} \mathrm{m}^{-1}$ ) devem ser monitorados e controlados periodicamente (Furlani et al., 1999). O controle do $\mathrm{pH}$ é relevante para a manutenção da integridade das membranas e para evitar a precipitação de micronutrientes como ferro, boro e manganês ou o fósforo (Martinez, 2002). A condutividade elétrica encontra-se diretamente associada à concentração iônica e à absorção dos nutrientes pela cultura ao longo do seu desenvolvimento (Marschner, 1995).

O objetivo deste trabalho foi avaliar respostas de crescimento e produtividade de três cultivares de tomateiro em sistema de cultivo hidropônico do tipo NFT, sob diferentes concentrações iônicas da solução nutritiva, nas condições de Seropédica, RJ.

\section{MATERIAL E MÉTODOS}

O experimento foi conduzido em casa de vegetação, localizada no De- partamento de Solos, Instituto de Agronomia, Universidade Federal Rural do Rio de Janeiro, no período de junho a dezembro de 2004. As condições climáticas do período em estudo encontramse na Figura 1.

Os tratamentos foram três cultivares de tomate (UC-82, T-93 e Saladinha) e três concentrações iônicas $(50,75$ e $100 \%$ ) da solução nutritiva de Hoagland \& Arnon (1950), arranjados como fatorial $3 \times 3$, no delineamento inteiramente casualizado, com três repetições e cinco plantas por parcela. As cultivares de tomateiro tinham as seguintes características: UC-82, de crescimento determinado, com ciclo de 110 dias e massa de fruto de 110g; Saladinha, de crescimento determinado, com ciclo de 110 dias e massa de fruto de $180 \mathrm{~g}$; e T-93, de crescimento indeterminado, com ciclo de 100 dias e massa de fruto de $220 \mathrm{~g}$.

As sementes foram colocadas para germinar em espuma fenólica com 216 células por placa. Utilizou-se câmara de germinação para o controle da temperatura $\left(25^{\circ} \mathrm{C}\right.$ dia $/ 20^{\circ} \mathrm{C}$ noite $)$ e UR\% entre $60-70 \%$, durante 96 horas, até a emissão do hipocótilo. Logo após a germinação, as mudas foram supridas com solução de Hoagland \& Arnon (1950) a $1 /$ de concentração iônica e conduzidas em fitotron, sob iluminação artificial

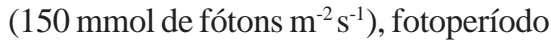
de 11 horas, temperaturas diurnas de $26^{\circ} \mathrm{C}$ e noturnas de $21^{\circ} \mathrm{C}$ e umidade relativa entre $60-70 \%$. Aos 15 dias após germinação (DAG), as mudas receberam solução de Hoagland \& Arnon (1950) diluída a 1/4 de concentração iônica. Aos 30 DAG, as plântulas foram transplantadas para os canais definitivos de cultivo. $\mathrm{O}$ espaçamento foi de 0,50 $\mathrm{m}$ entre plantas, $0,60 \mathrm{~m}$ entre linhas duplas com 1,00 m de corredor, totalizando quinze plantas por canal. Foram utilizados nove canais de cultivo com $11 \mathrm{~m}$ de comprimento.

A vazão da solução nutritiva foi de $4 \mathrm{~L} \mathrm{~min}^{-1}$ e o fluxo foi programado em intervalos pré-determinados (45 minutos com irrigação e 15 minutos sem irrigação), utilizando-se temporizadores eletro-mecânicos, seguindo-se recomendações de Moraes (1997). Para cada tratamento, foi utilizado um reservatório com capacidade de $1500 \mathrm{~L}$ de solução nutritiva.

Na formulação da solução nutritiva, utilizaram-se sais comerciais descritos na Tabela 1. O acompanhamento da condutividade elétrica (CE), $\mathrm{pH}$ e temperatura da solução nutritiva foi realizado diariamente, nos horários de 9:00 h, 11:00 h e 15:00 h. As soluções foram renovadas quinzenalmente, de acordo com os protocolos descritos por Martinez (2002) e Moraes (1997). As correções do $\mathrm{pH}$ foram realizadas, quando necessárias, logo após as leituras das 9:00h com soluções $0,1 \mathrm{~mol} \mathrm{~L}^{-1}$ de $\mathrm{KOH}$ e de $\mathrm{H}_{2} \mathrm{SO}_{4}$, mantendo-se pH 5,5 \pm 0,5. A reposição de sais foi realizada de acordo com Furlani et al. (1999), logo após a leitura da CE às 9:00 h. Os valores iniciais e de reposição da $\mathrm{CE}$ foram de $1,44 \mathrm{dS} \mathrm{m}^{-1}$ para o tratamento $50 \% ; 2,16$ $\mathrm{dS} \mathrm{m} \mathrm{m}^{-1}$ para $75 \%$ e de $2,88 \mathrm{dS} \mathrm{m}^{-1}$ em $100 \%$.

O controle fitossanitário foi realizado seguindo-se as técnicas descritas por Penteado (2001); Campanola (2003); Feitosa \& Cruz (2003).

$\mathrm{Na}$ fase produtiva foram realizadas nove coletas para a quantificação do número de frutos (NF), massa fresca por fruto (MFF), massa fresca total de frutos por planta (MFP), teor de sólidos solúveis totais ( ${ }^{\circ}$ Brix) e produtividade. Considerou-se como ponto de colheita agronômico frutos de coloração rosaesverdeado (Moraes, 1997). A produti- 
vidade foi obtida através da multiplicação da quantidade de frutos por planta, da massa fresca total de frutos por planta e da quantidade de plantas por metro quadrado da área experimental. O valor obtido em $\mathrm{kg}$ fruto $\mathrm{m}^{-2}$ foi convertido em $t$ ha $^{-1}$.

Foram coletadas quinze plantas por tratamento, aos 138 dias após transplante (DAT), para avaliação das características fenológicas altura; massas frescas da parte aérea (MFPA), de folhas (MFF) e de hastes (caule+pecíolo); e massas secas das folhas (MSF) e das hastes (MSH) das plantas.

A análise estatística foi realizada com auxílio do programa SAS (SAS Institute, 1993). Utilizou-se o teste de Tukey para comparação de médias, a 5\% de probabilidade.

\section{RESULTADOS E DISCUSSÃO}

A altura e o acúmulo de massa fresca e seca nas plantas das cultivares Saladinha e T-93 não foram alteradas pelas concentrações iônicas em todos os tratamentos estudados. Por outro lado, foram observadas diferenças quanto ao acúmulo de massa fresca de folhas e hastes em plantas da cultivar UC-82 na solução de Hoagland a $75 \%$ da concentração iônica (Tabela 2). Este maior acúmulo de massa fresca pode ser devido a maior adaptabilidade da cultivar à

Tabela 1. Concentrações de nutrientes da solução de Hoagland ajustada aos tratamentos 50\%, 75\% e 100\% de concentração iônica. Seropédica, UFRRJ, 2004.

\begin{tabular}{lrcr}
\hline Nutrientes & \multicolumn{3}{c}{ Concentração $\left(\mathbf{m g ~ L}^{-1}\right)$} \\
\cline { 2 - 4 } Macro & $\mathbf{5 0 \%}$ & $\mathbf{7 5 \%}$ & $\mathbf{1 0 0} \%$ \\
\hline Nitrato de cálcio & 422,58 & 633,86 & 845,15 \\
Nitrato de potássio & 284,21 & 426,32 & 568,42 \\
Monoamônio fosfato (MAP) & 25,36 & 38,03 & 50,71 \\
Monofosfato de potássio (MKP) & 34,25 & 51,38 & 68,50 \\
Sulfato de magnésio & 240,00 & 360,00 & 480,00 \\
Cloreto de potássio & 6,40 & 9,60 & 12,80 \\
\hline Micro & \multicolumn{3}{c}{ Concentração (mg L-1) } \\
\hline Sulfato de manganês & 0,960 & 1,440 \\
Sulfato de zinco & 0,115 & 0,172 & 1,920 \\
Ácido bórico & 1,470 & 2,205 & 0,230 \\
Sulfato de cobre & 0,075 & 0,112 & 2,940 \\
Molibdato de sódio & 0,015 & 0,022 & 0,150 \\
FeEDDHA (6\%) & 5,250 & 7,880 & 10,500 \\
\hline
\end{tabular}

Adaptado de Bugbee (1995).

soluções nutritivas com potencial hídrico $\left(\Psi_{\mathrm{H}}\right)$ mais positivo e, conseqüentemente, a maior energia livre da água em solução (Taiz \& Zeiger, 2004).

As cultivares Saladinha e T-93 produziram frutos com massa fresca média inferior ao seu potencial genético, considerando-se que eram esperadas massas de $110 \mathrm{~g}$ e $220 \mathrm{~g}$, respectivamente (SAKATA, 2004; ISLA, 2004). Essa resposta pode ter ocorrido devido à adaptação das cultivares às condições climáticas da casa de vegetação no estádio reprodutivo e à não realização do raleio de frutos. A cultivar UC-82 apresentou massa fresca média de frutos superior à citada por Takii (2004) no tratamento $75 \%$ (Tabela 2).

A massa fresca de frutos, o número total de frutos (NTF) e a massa de frutos por planta (MFP) não diferiram estatisticamente nos tratamentos estudados.

De modo geral, os dados obtidos neste trabalho ajustam-se aos de Cavarianni et al. (2005); Cometti \& Mary (2005); Cassiano et al. (2005) e Dulgheroff et al. (2005) que, ao cultivarem rúcula, alface, sálvia e mostarda, respectivamente, constataram que a diluição das soluções nutritivas não in-

Tabela 2. Desenvolvimento das cultivares de tomateiro UC-82, Saladinha e T-93, nos tratamentos 50\%, 75\% e 100\% de concentração iônica da solução nutritiva de Hoagland, conduzidos em casa de vegetação em Seropédica, nos meses de junho a dezembro de 2004. Seropédica, UFRRJ, 2004.

\begin{tabular}{|c|c|c|c|c|c|c|c|c|c|}
\hline \multirow{2}{*}{ Variáveis } & \multicolumn{3}{|c|}{ Cv. UC-82 } & \multicolumn{3}{|c|}{ Cv. Saladinha } & \multicolumn{3}{|c|}{ Cv. T-93 } \\
\hline & $50 \%$ & $75 \%$ & $100 \%$ & $50 \%$ & $75 \%$ & $100 \%$ & $50 \%$ & $75 \%$ & $100 \%$ \\
\hline Altura $(\mathrm{cm})$ & $84,0 \mathrm{a}$ & $109,0 \mathrm{a}$ & $97,0 \mathrm{a}$ & $182,0 \mathrm{a}$ & $188,0 \mathrm{a}$ & $97,0 \mathrm{a}$ & $130,0 \mathrm{a}$ & $127,0 \mathrm{a}$ & 122,0 a \\
\hline Massa fresca da parte aérea (g planta-1) & $346,9 \mathrm{~b}$ & $1.314,9 \mathrm{a}$ & $734,8 \mathrm{~b}$ & $1.488,0 \mathrm{a}$ & $1.678,4 \mathrm{a}$ & $1.529,4 \mathrm{a}$ & 822,0 a & $983,0 \mathrm{a}$ & 968,4 a \\
\hline Massa fresca de folha (g planta ${ }^{-1}$ ) & $558,4 \mathrm{~b}$ & 889,2 a & $482,6 \mathrm{~b}$ & 983,6 a & $1.136,4 \mathrm{a}$ & 948,2 a & 561,8 a & 703,4 a & 700,2 a \\
\hline Massa fresca de hastes (g planta-1 $)$ & $269,4 a b$ & 393,0 a & $215,0 \mathrm{~b}$ & 412,8 a & 461,4 a & 4794 a & $216,0 \mathrm{a}$ & 227,4 a & 217,4 a \\
\hline Massa seca da parte aérea (g planta-1) & 154,9 a & 206,6 a & 172,3 a & 250,9 a & 249,5 a & 177,4 a & 150,8 a & 203,4 a & 210,8 a \\
\hline Massa seca de folha (g planta-1) & $89,1 \mathrm{a}$ & 121,1 a & 83,8 a & 144,3 a & 151,1 a & 95,3 a & 85,51 a & 120,8 a & $137,1 \mathrm{a}$ \\
\hline Massa seca de hastes (g planta-1) & $52,6 \mathrm{a}$ & $59,3 \mathrm{a}$ & 75,2 a & 85,9 a & $74,5 \mathrm{a}$ & $57,1 \mathrm{a}$ & $46,1 \mathrm{a}$ & $61,1 \mathrm{a}$ & 59,2 a \\
\hline Massa de fruto $\left(\mathrm{g}_{\text {fruto }}{ }^{-1}\right)$ & 57,9 a & $72,7 \mathrm{a}$ & $59,1 \mathrm{a}$ & $100,0 \mathrm{a}$ & 101,0 a & $85,1 \mathrm{a}$ & $127,1 \mathrm{a}$ & 120,7 a & $141,3 \mathrm{a}$ \\
\hline $\begin{array}{l}\text { Número total de frutos por planta (frutos } \\
\text { planta }^{-1} \text { ) }\end{array}$ & $19,4 \mathrm{a}$ & $26,8 \mathrm{a}$ & 32,6 a & 30,8 a & 41,0 a & $29,2 \mathrm{a}$ & $24,4 a$ & 29,8 a & 26,0 a \\
\hline Massa de frutos por planta (kg planta-1) & $1,2 \mathrm{a}$ & $1,8 \mathrm{a}$ & 1,9 a & $3,1 \mathrm{a}$ & $4,1 \mathrm{a}$ & $2,5 \mathrm{a}$ & $3,1 \mathrm{a}$ & $3,7 \mathrm{a}$ & $3,7 \mathrm{a}$ \\
\hline Sólidos solúveis totais $\left({ }^{\circ} \mathrm{BRIX}\right)$ & $3,0 \mathrm{a}$ & $3,2 \mathrm{a}$ & $2,8 \mathrm{a}$ & $2,8 \mathrm{c}$ & 3,9 a & $3,1 \mathrm{~b}$ & 3,9 a & $3,5 \mathrm{a}$ & $3,5 \mathrm{a}$ \\
\hline Produtividade $\left(\mathrm{t} \mathrm{ha}^{-1}\right)$ & $36,0 \mathrm{~b}$ & $85,5 \mathrm{a}$ & 83,9 a & $47,0 \mathrm{~b}$ & $101,3 \mathrm{a}$ & $94,22 a b$ & $50,34 \mathrm{~b}$ & $76,26 \mathrm{ab}$ & 99,09 a \\
\hline CV (\%) & & 15,73 & & & 30,00 & & & 28,72 & \\
\hline
\end{tabular}

Dentro de cada tratamento, médias na mesma linha, seguidas por letras iguais não diferem entre si pelo teste de Tukey a 5\% de probabilidade. 

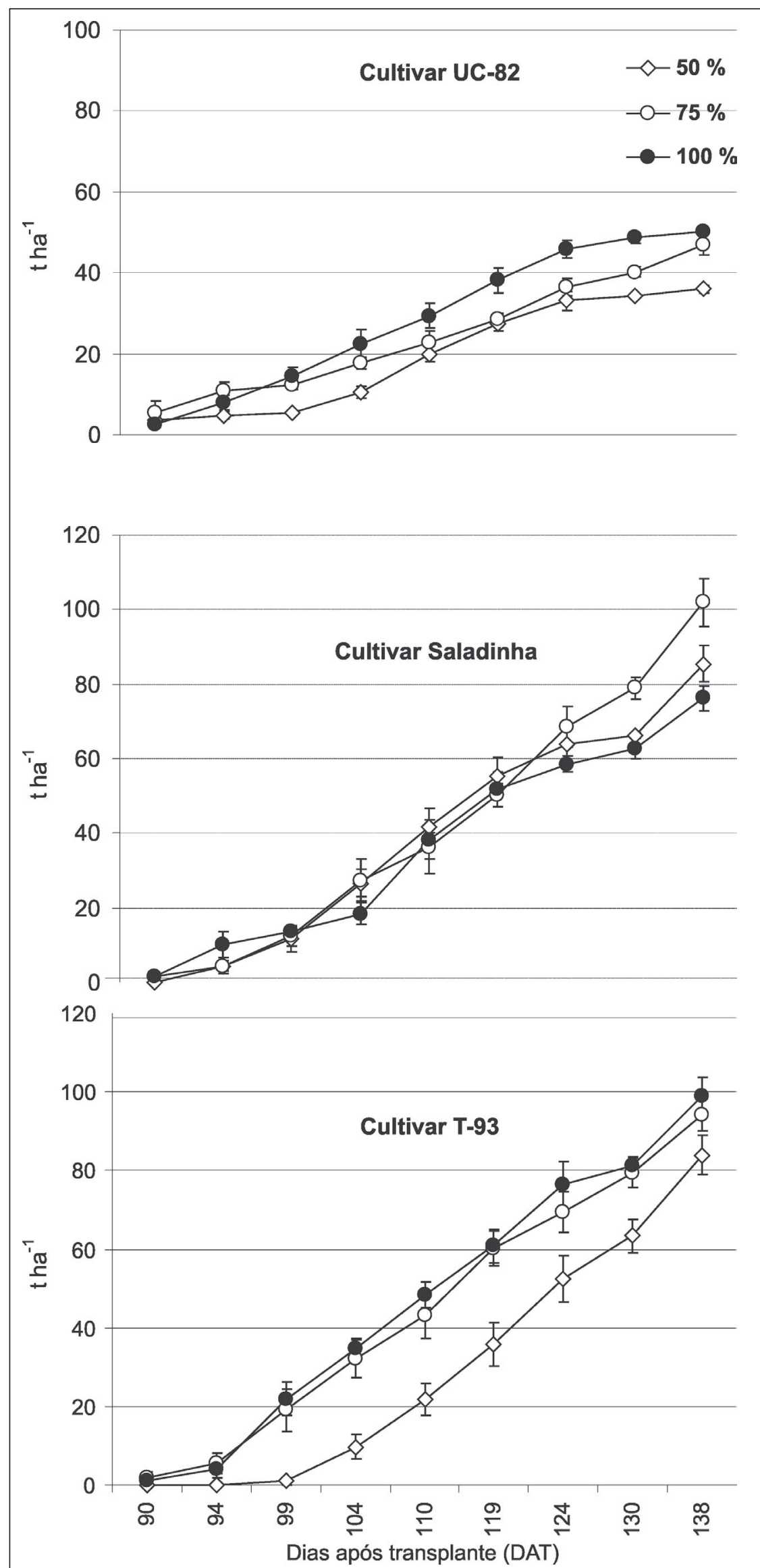

Figura 2. Produtividade das cultivares de tomateiro UC-82, Saladinha e T-93 nos tratamentos 50\%, 75\% e 100\% da concentração iônica de Hoagland. Seropédica, UFRRJ, 2004. fluenciou o acúmulo de massa no cultivo dessas espécies. Para o cultivo do tomateiro, Torres et al. (2004) verificaram que, sob diferentes concentrações iônicas de solução nutritiva, as características altura, diâmetro de caule, área foliar e massa seca das folhas, assim como massa seca dos frutos, produção e produtividade não diferiram significativamente.

Os teores de sólidos solúveis totais somente diferiram estatisticamente na cultivar Saladinha (Tabela 2). Os valores médios de ${ }^{\circ}$ Brix obtidos neste experimento estão abaixo dos $4,0{ }^{\circ}$ Brix que, segundo Silva e Giordano (2000) devem ser o mínimo para a matéria-prima recebida pelas indústrias no Brasil. Por outro lado, diversos trabalhos têm demonstrado que as médias obtidas em cultivos protegidos de tomate dificilmente alcançam $4,0{ }^{\circ}$ Brix ou mais. Portanto pesquisas direcionadas à adequação da nutrição mineral do tomateiro ao acréscimo no teor de sólidos solúveis nos frutos são de primordial importância para a melhoria em qualidade no cultivo de tomateiro para fins de comercialização.

A cultivar UC-82 apresentou as maiores produtividades nos tratamentos $75 \%$ e $100 \%$ da concentração iônica da solução de Hoagland (Figura 2). Também, a produtividade da cultivar Saladinha foi superior no tratamento $75 \%$, enquanto a cultivar T-93 apresentou maior produtividade no tratamento $100 \%$. Essa cultivar foi mais tardia, uma vez que a colheita foi retardada no tratamento $50 \%$.

As produtividades observadas neste trabalho, em média, foram superiores à produtividade média do tomateiro no Brasil em cultivo tradicional, que está em torno de $55 \mathrm{t} \mathrm{ha}^{-1}$ (Canaçado-Júnior et al., 2003). Cabe ressaltar que, em ambiente protegido, Marques et al. (2000), cultivando tomateiros cultivar Carmem, obtiveram produtividades médias de $77 \mathrm{t} \mathrm{ha}^{-1}$. Por outro lado, Carvalho et al. (2000), testando a adaptação de tomateiros de hábitos de crescimento determinado e semideterminado, em casa de vegetação, no verão em Brasília, observaram produção média de 52 t ha $^{-1}$. Schmidt \& Santos (2000) destacam que uma solução nutritiva equili- 
brada é o princípio básico para a obtenção de qualidade em cultivos hidropônicos comerciais e cultivando tomateiros do tipo salada em hidroponia, obtiveram valores de produtividade maiores que as médias nacionais, superando $100 \mathrm{t} \mathrm{ha}^{-1}$.

De modo geral, as diferentes concentrações iônicas das soluções nutritivas, nas condições em que foi desenvolvido o trabalho, não influenciaram a produtividade e o acúmulo de massa dos tomateiros. Portanto, é recomendável o uso de soluções de menor concentração iônica para o cultivo de tomateiros UC82, Saladinha e T-93 em sistema hidropônico NFT, nas condições climáticas de Seropédica, Rio de Janeiro.

\section{AGRADECIMENTOS}

Os autores agradecem à CAPES, pelo apoio financeiro; à UFRRJ, CPGACS, Labfer, Depto. de Solos e Depto. de Ciências Fisiológicas, pela infraestrutura disponibilizada para a realização deste trabalho; às empresas Sakata, Takii, Isla, Hidrogood e Qualifértil, pela disponibilização de sementes, canais e nutrientes.

\section{REFERÊNCIAS}

BUGBEE B. 1995. Nutrient management in recirculating hydroponic culture. In: Annual Conference on Hydroponics, 16. Arizona: Hydroponic Society of America, p. 15-30.

CAMPANOLA C; BETTIOL W. 2003. Métodos alternativos de controle fitossanitário. Jaguariúna: Embrapa Meio Ambiente. 279p.

CANÇADO-JÚNIOR FL; CAMARGO-FILHO WP; ESTANISLAU MLL; PAIVA BM; MAZZEI AR; ALVES HS. 2003. Aspectos econômicos da produção e comercialização do tomate para mesa. Informe Agropecuário 24: 7-18.

CARVALHO VD. 2000. Características químicas e industriais do tomate. Informe Agropecuário 6: 63-68.

CASSIANO CV; SANTOS VB; LUZ JMQ; HABER LL; DIAS PAA. 2005. Produção hidropônica de sálvia (Salvia officinallis) em diferentes concentrações de solução nutritiva. Horticultura Brasileira 23: 466
CAVARIANNI RL; CORRADI MM; CECÍLIOFILHO AB; CAZETTA JO. 2005. Produtividade de cultivares de rúcula em função da diluição da solução nutritiva. Horticultura Brasileira 23: 406.

COMETTI NN; MARY W. 2005. Efeito da concentração da solução nutritiva no crescimento do sistema radicular da alface em cultivo hidropônico - sistema NFT. Horticultura Brasileira 23: 461.

COMETTI NN. 2003. Nutrição mineral da alface (Lactuca sativa L.) em cultura hidropônica - sistema NFT. Seropédica: UFRRJ. 128p. (Tese doutorado).

COSTA CP; RIZZO AAN; GAYOSO AAFT; GOTO R. 2000. Concentrações de nitrogênio e relações $\mathrm{NO}_{3} / \mathrm{NH}_{4}$ na produção e crescimento do tomateiro híbrido Momotaro em solução nutritiva. Horticultura Brasileira Brasília 18: 783-784.

DULGHEROFF BM; LUZ JMQ; SANTOS VB; SILVA MAD; DIAS PAA. 2005. Cultivo hidropônico de mostarda (Brassica juncea) em diferentes concentrações de solução nutritiva. Horticultura Brasileira 23: 470.

FAQUIN V; FURTINI NETO AE; VILELA LAA. 1996. Produção de alface em hidroponia. Lavras: UFLA. 50p.

FEITOSA FAA; CRUZ GF. 2003. Controle de pragas e doenças de flores e hortaliças. Fortaleza: Instituto Frutal. 223p.

FURLAN RA; FOLEGATTI MV. 2000. Efeito da nebulização na redução da temperatura do ar em ambiente protegido. Horticultura Brasileira 18: 203-204.

FURLANI PR; SILVEIRA LCP; BOLONHEZI D; FAQUIN V. 1999. Cultivo hidropônico de plantas. Campinas: Instituto Agronômico. 50p. (Boletim técnico, 180).

GOTO R; TIVELLI SW. 1998. Produção de hortaliças em ambiente protegido: condições subtropicais. São Paulo: Fundações Editoras da UNESP. 309p.

HAAG HP; DECHEN AR; CARMELLO QQC; MONTEIRO FA. 1993. Princípios de nutrição mineral: aspectos gerais. In: SIMPÓSIO SOBRE NUTRIÇÃO E ADUBAÇÃO DE HORTALIÇAS. Anais... Piracicaba: Associação Brasileira para Pesquisa da Potassa e do Fosfato. p. 51-73.

HOAGLAND DR; ARNON DI. 1950. The waterculture method for growing plants without soil. Berkeley: Agric. Exp. Stn., Univ. of California. (Circ. 347).

ISLA. 2004, 15 de novembro. Sementes: hortaliças. Disponível em www.isla.com.br

LUZ JMQ; HABRE LL; DIAS PAA. 2005. Produção hidropônica de sálvia (Salvia officinalis) em diferentes concentrações de solução nutritiva. Horticultura Brasileira 23: 466.
MARQUES FC; TIBOLA AJ; PRIEBE AJ. 2000. Cultivo protegido de cultivares de tomateiro submetidas ou não à desbrota. Horticultura Brasileira 18: 190-191.

MARSCHNER H. 1995. Mineral nutrition of higher plants. Academic Press, 2.ed., London. $889 \mathrm{p}$.

MARTINEZ HEP. 2002. O uso do cultivo hidropônico de plantas em pesquisa. Viçosa: UFV. 61p.

MARY W. 1997. Produção sazonal de cultivares de alface sob estrutura de proteção tipo túnel alto, em clima tropical, com dois tipos de cobertura morta. Seropédica: UFRRJ. 150p (Tese mestrado).

MORAES CAG. 1997. HIDROPONIA: Como cultivar tomates em sistema NFT. 1.ed. Jundiaí: DISQ Editora. 143p.

PENTEADO SR. 2001. Defensivos alternativos e naturais: para uma agricultura saudável. 3 . ed. Campinas. 96p.

SAS INSTITUTE. 1993. SAS/STAT User's guide: Version 6.12, 4.ed. Carey, Inc: SAS Institute. 2: 891-996.

SAKATA. 2004, 14 de novembro. Catálogo de produtos: hortaliças. Disponível em www.sakata.com.br

SCHMIDT D; SANTOS SS; BONNECARRÈRE RAG; PILAU FG. 2000. Potencial produtivo de tomate cultivado com alta densidade, em hidroponia. Horticultura Brasileira 18: 273274.

SILVA JBC; GIORDANO LB. 2000. Tomate para processamento industrial. Brasília: Embrapa Hortaliças/Ministério da Agricultura e Abastecimento. $168 \mathrm{p}$.

TAIZ L; ZEIGER E. 2004. Fisiologia Vegetal. Trad. SANTAREM ER; [et al.]. 3.ed. Porto Alegre: Artmed. 719p.

TAKII. 2004, 14 de novembro. Menu inicial: tomate. Disponível em www.takii.com.br

TEIXEIRA NT. 1996. Hidroponia: uma alternativa para pequenas áreas. Guaíba: Agropecuária. 86p.

TORRES OGV; GARCIA PS; CASTILLO GAB; MENDOZA MNR; LÓPEZ CT; VILLA MS; SORIANO EC. 2004. Desarrollo y producción de tomate (Lycopersicon esculentum mill.) con solución nutritiva específica para cada etapa fenológica. In: REUNIÃO BRASILEIRA DE FERTILIDADE DO SOLO E NUTRIÇÃO DE PLANTAS, FERTBIO, 26. Resumos... Lajes: (CD-ROOM). 
O arquivo disponível sofreu correções conforme ERRATA publicada no Volume 24 Número 3 da revista. 